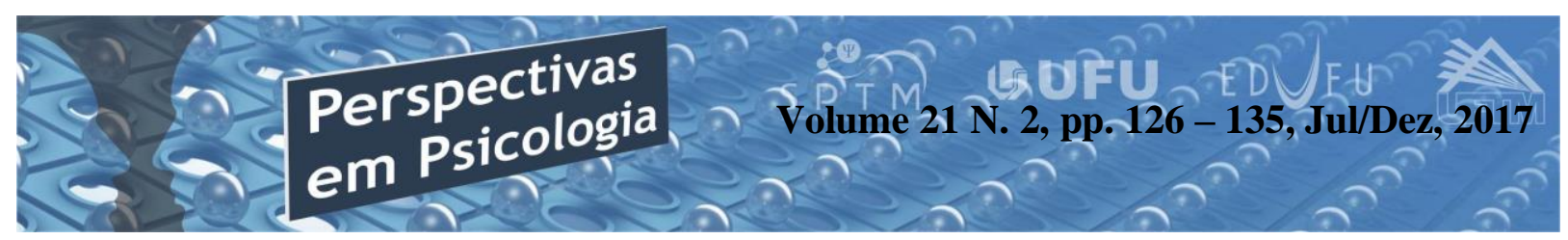

\title{
TEMPO DE DEMISSÃO EM TEMPOS LÍQUIDOS
}

\author{
Maria Gabriela Pires de Lacerda Lima \\ Rhennan Lázaro de Paulo Lima \\ Roberta Almeida Elias \\ Serigne Ababacar Cissé Ba \\ (Universidade Federal de Goiás, Regional Catalão - UFG/RC)
}

\begin{abstract}
Resumo
Este artigo apresenta uma breve reflexão sobre o fim dos relacionamentos pós demissão e as ilusões que os indivíduos têm de que nas relações de trabalho e produção com as empresas há amor, proteção e poder. Com o intuito de demonstrar que essas relações no contexto atual são frágeis e se moldam de acordo com o que convém, naturalmente avessos à duração e estabilidade, foi trazida as teorias de "tempos líquidos" e "amor líquido" do filósofo polonês Zigmunt Bauman. Percebe-se, por fim, que as relações sociais necessitam com urgência de mudanças rápidas. $\mathrm{O}$ agente transformador são os próprios indivíduos, que não podem perder as esperanças de mudar o destino da humanidade.
\end{abstract}

Palavras-chave: desemprego; tempos líquidos; amor líquido.

\section{Abstract}

\section{Time of Demission in Liquid Times}

This paper presents a brief reflection on the end of post-dismissal relationships and the illusions that individuals have that in the relations of work and production with the companies there is love, protection and power. In order to demonstrate that these relations in the present context are fragile and conform to what is appropriate, naturally averse to duration and stability, the "liquid times" and "liquid love" theories by the Polish philosopher Zigmunt Bauman were brought. It can be seen, then, that social relations urgently need rapid change. The transforming agent is the individuals themselves, who should not lose hope of changing the destiny of humanity.

Keywords: unemployment; liquid times; liquid love.

\section{Introdução}

Segundo Castel (1998), o trabalho segue sendo uma referência não só econômica, mas também psicológica, cultural e simbólica, como demonstra a reação dos que não o têm. Hayes e Nutman (1981) demonstram que o indivíduo se enxerga em suas relações sociais, ou seja, ele é o que os outros o veem. Dessa forma, 
nas atividades sociais, o homem se reconhece e cria a sua identidade.

Ao perder o emprego, o indivíduo sofre uma ruptura em suas relações sociais e isso afeta diretamente o modo como ele mesmo se reconhece, como imagina ser reconhecido pelos outros e, consequentemente, a sua identidade. A perda do emprego é motivo de grave crise pessoal, gera traumas para o indivíduo e afeta a sua vida familiar. Além da fonte de sobrevivência, com o desemprego perde-se identidade e vínculos sociais (Jahoda,1982; Eisenberg \& Lazarfedl, 1938; Caldas, 2000; Seligmann-Silva, 1997). A atual fragilidade das relações sociais é apontada pelo sociólogo polonês Zigmunt Bauman, estudioso do mundo contemporâneo, por meio dos conceitos de "tempos líquidos", "modernidade líquida", "amor líquido" e "vida líquida". Líquidos, porque tudo muda rapidamente. Nada é feito para durar, para ser "sólido". As relações sociais (pessoais, de trabalho, de comunidade) não são mais estáveis, concretas, duráveis". (Bauman, 2007, p. 13)

Como o desemprego é causa para a perda das relações sociais - e relações humanas envolvem afetividade - faz-se necessária o conceito de "amor líquido", a fim de se verificar o fim da relação do indivíduo com a organização $-\mathrm{o}$ desemprego - que pode ser compreendido a partir das ideias apresentadas por Bauman.

Bauman, um dos mais produtivos sociólogos da atualidade, utiliza a metáfora do líquido para caracterizar a modernidade (2001), o amor (2004), os tempos (2007) e a vida (2008), porque "os líquidos se movem facilmente, fluem, escorrem, esvaem-se, respingam" (Bauman, 2001, p. $8)$.

O "amor líquido", para Bauman, mostra a fragilidade dos laços humanos no que tange à afetividade e a desconstrução de sua solidez, por isso as relações estão em constantes mudanças, com "prazo de validade" e superficiais.Diante disto, a preferência por Bauman foi uma escolha deliberada, com o intuito de compreensão das relações sociais humanas, numa perspectiva das relações desconstruídas após o processo de demissão.

\section{Referencial Teórico}

O trabalho é a fonte de sobrevivência do homem, gerador do recurso que é capaz de suprir suas necessidades, além de influenciador do estado psicológico, pois, a ocupação do tempo, sentir-se útil, produtivo, as relações afetivas, são elementos que influenciam no comportamento do ser humano.

Segundo Chahad e Chahad (2005, p.184), "o trabalho é fonte de sustento, 
acúmulo de capitais e afeta o quadro econômico mundial. Mas, tão importante quanto isso, o trabalho é, também, um fator fundamental para a Psicologia”.

Os autores Chahad e Chahad (2005) pontuam sobre essa percepção que dá ao trabalho o caminho para suprir as necessidades humanas, mas dá ênfase a abertura psicológica gerada por seu exercício, pois o homem em atividade irá desenvolver sua criatividade, relações sociais e encontrar sua identidade.

Assim, a demissão gera efeitos contrários aos do trabalho. O indivíduo, sofrerá com a falta de dinheiro para sua sobrevivência, contrairá dívidas, enfrentará crises e será atacado pela baixa autoestima - eis exemplos de algumas das consequências do desemprego.

Machado, Hernandes e Moraes (2008)revelam que o trabalho faz parte da construção da identidade do ser humano, e estudar os efeitos da demissão torna-se uma ação importante para compreender a identidade do indivíduo. Nas últimas décadas passamos por grandes mudanças no cenário político, econômico e industrial, principalmente pelo avanço tecnológico, que transformou o trabalho, o que fez com que novas profissões surgissem e outras deixassem de existir, como por exemplo, a função de datilógrafo, extinta, e o profissional da página virtual da empresa.Nesse cenário, o indivíduo deve aprender a adaptar-se e procurar capacitarse.

Segundo Machado, Hernandes e Moraes (2008, p.8), “a demissão está simbolicamente associada ao fracasso e, muito embora algumas situações não sejam consequências do fracasso individual, mesmo assim elas geram insegurança na pessoa". Por isso, estudar os efeitos da demissão no mundo do trabalho que vem sofrendo intensas transformações, é muito necessário para compreender a identidade e a afetividade humanas que vão sendo construídas.

Bauman (2007, p.75) revela que:

[...] estar sem emprego implica ser descartável, talvez até ser descartado de uma vez por todas, destinado ao lixo do 'progresso econômico' - essa mudança que se reduz, em última instância a fazer o mesmo trabalho e obter os mesmos resultados econômicos, porém com uma força de trabalho mais reduzida e com "custos de mão de obra menores que antes. (Bauman, 2007, p.75).

E, por que as empresas demitem trabalhadores? Porque querem com uma força de trabalho menor, portanto, com menores custos com mão de obra, obter a mesma produção ou uma maior e, assim, lucrar mais. 
A demissão, por justa causa ou não, deixa o indivíduo à mercê do destino, desocupa-o e quebra o seu relacionamento com o grupo de trabalho. As bruscas mudanças das relações sociais na pósmodernidade são $o$ maior sinal dos “tempos líquidos". Conforme Basílio (2010, p.441) "o conceito recorrente, que permeia tempos líquidos,é o da insegurança existencial". Assim, a ideia de “tempos líquidos" segundo Bauman (2007, p. 13) " [...] traz à mente da maioria de nós a experiência aterrorizante de uma população heterônoma, infeliz e vulnerável, confrontada e possivelmente sobrepujada por forças que não controla nem entende totalmente". Numa Modernidade Líquida, regida por tempos líquidos, não só a vida como também o amor pode ser líquido.

Bauman (2004) utiliza a idéia de "Amor líquido" para compreender a crise atual das relações afetivas, a fragilidade nos laços humanos. Como, "nada é para durar", as relações afetivas estabelecidas entre os indivíduos também não o são, principalmente no mundo do trabalho. Com toda a vida liquidificada e diante de graves problemas (sociais, ambientais, econômicos, etc) existentes, qual seria a solução, haveria uma solução?

Segundo Costa (2015, p.62), “o amor sólido é o único caminho para refazer as utopias das relações humanas, amor dado e acolhido em forma de amorpróprio". Não se deve deixar quebrar tão facilmente as relações humanas, deve-se lutar pela segurança e confiança nas relações com as pessoas.

O amor líquido impede a relação entre os indivíduos de forma proveitosa e que seja mútua no crescimento pessoal e profissional. $\mathrm{O}$ individualismo $\mathrm{e} \quad \mathrm{a}$ desconfiança são elementos que dificultam a afetividade, não só no trabalho como também em várias outras áreas da vida. Costa (2015, p.71) revela que "a falta de relações profundas e confiáveis criou uma situação de fronteira dentro de casa, pois o outro é como um estranho ou um estrangeiro das alfândegas estatais". Seja dentro de casa ou no ambiente de trabalho a liquidez das relações traz sérias consequências para a sociedade nesta fase da história em que se vive.

O amor é o sentimento de destaque nas relações humanas. No trabalho, também há relações afetivas entre o grupo e esses laços podem se tornar fortes na busca pelos resultados pessoais e organizacionais. Costa (2015, p.59) define o amor como "o poderoso sentimento que une as pessoas, aproxima os estranhos e consolida a sociedade, tecendo urdiduras de vidas engajadas." Mas, segundo o mesmo autor, "o mundo líquido-moderno atingiu a esfera mais profunda dos sentimentos, nivelando amor e desejo 
como gêmeos univitelinos" (p.60). Assim, o amor como amor líquido, passou a ser confundido com desejo. As relações afetivas enfraquecem, sobrepujadas pela força do desejo em ter ou conquistar.

Diante de todas as mudanças ocorridas na história do mundo, a globalização é a que nos permitiu o maior avanço, seja na comunicação, transporte, produção e etc. Mas trouxe junto a ela a tecnologia que nos postos de trabalho vem substituindo a força humana por máquinas. Frattari (2008, p.398) salienta que "a confiança e a esperança que depositamos na tecnologia em busca de um mundo melhor e mais seguro possa ser frustrada e constitui também uma nova e fértil fonte de medo nos tempos líquido-modernos". Não apenas na produção, pois a tecnologia cria um alcance na rede de relacionamento incrível entre as pessoas, tornando fraca as relações afetivas pelas inúmeras possibilidades de amigos, parceiros e negócios.

Para Bauman (2004, p. 46), o estilo de vida consumista trataas relações afetivas como objetos de consumo, cuja avaliação é feita pela quantidade de prazer que proporcionam. Assim, os valores intrínsecos dos indivíduos, os valores humanos, estão praticamente desaparecendo, assiste-se ao fim da solidariedade humana e à vitória do mercado consumidor. $\mathrm{O}$ autor ressalta ainda que antes de demonstrar qualquer gesto de afeto as pessoas se questionam com dúvidas como "por que devo fazer isso? e "que benefício me trará?". O nível de exigência para amar o próximo, e, neste caso qualquer próximo, só aumenta.

Com isso, Bauman (2004, p. 52) apresenta a definição de Giddens para "relacionamento puro", para quem os relacionamentos se constroem "pelo que cada um pode ganhar" e "continuam "apenas enquanto ambas as partes imaginam que estão proporcionando, a cada uma, satisfações suficientes para permanecerem na relação". Mas, nos tempos líquidos as necessidades, afetivas ou não, mudam rapidamente e são cada vez mais difíceis de serem satisfeitas, são cada vez mais urgentes, o que não permite aos indivíduos a construção, o cultivo, dos diversos tipos de amores não líquidos.

Desse modo, inseguranças de todo tipo caracterizam o período pós-moderno. Frattari (2008, p.398) destaca que: "vivemos, portanto, em um mundo de incertezas. Sentimo-nos mais ameaçados, atemorizados e apaixonados por tudo que se refira à segurança do que a maioria das sociedades de que se têm relato". Enfim, vive-se com muito mais medo - de tudo - e isso leva à confusão entre o que é problema e o que é solução, por exemplo, a nova tecnologia. 
Bauman (2004) ainda ressalta que o aprendizado diário obtido com as experiências vividas pelos indivíduos atualmente reforça a rejeição dos seres humanos uns pelos outros e a competição escancarada, impiedosa como forma para atingir a vitória - é o caso, por exemplo, do que se pode aprender com os reality shows, programas de televisão que contam com grande audiência.

Entre as inseguranças, o medo e as incertezas perenes à sociedade líquida, a demissão do emprego deixa os indivíduos totalmente vulneráveis. Além de o mercado de trabalho ser cada vez mais competitivo, as suas ofertas de trabalho que podem contribuir para o crescimento humano e com a satisfação das necessidades diversas são rarefeitas, praticamente não existem.

Para Bauman (2007), há uma grande instabilidade nas diversas áreas da vida, tais quais os empregos, os parceiros, as amizades. Como os vínculos humanos estão confortavelmente fracos, fica muito difícil praticar a solidariedade e compreender seus benefícios em tempos líquidos. Conforme Bauman (2007, p. 108), como o tempo flui, "o truque é se manter no ritmo das ondas". Mas, o medo, as incertezas e as inseguranças fazem com que as pessoas percam essa capacidade, passando a encarar ondas "normais" como tsunamis.

\section{Discussão}

O aumento do desemprego no mundo é resultado de transformações ocorridas na economia a partir da década de 80 e, consequentemente no modo de administrar as empresas, nas relações de trabalho e com a introdução de novas tecnologias.Aliada a estas questões, no Brasil a forte recessão econômica, de acordo com o Cadastro Geral de Empregados e Desempregados (CAGED), levou à perda de 1,32 milhões de postos de trabalho em 2016, segundo pior resultado da série histórica iniciada em 1992.

$\mathrm{O}$ desemprego que causa a ruptura das relações sociais construídas na organização; é um dos fatores que mais gera sofrimento para o indivíduo, como pode-se observar em exemplos de frases que expressam o sentimento em relação à demissão: "me senti totalmente perdida" e "sinto mesmo é um grande vazio" que demonstram como o desemprego causa impactos na vida do indivíduo.(Castelhano, 2006, p.9).

Conforme Castelhano (2006),numa organização há vários elementos de subjetividade e, no processo de perda do emprego, o indivíduo perde também a afetividade criada nas relações com outros indivíduos da organização. Com a ruptura, os vínculos de amor, proteção e poder, 
relações sólidas que o indivíduo supunha existirem, são desfeitas e ele constata, então, que tinha sido fantasia, uma ilusão, a de que esses laços afetivos eram consistentes e duradouros.

Para a compreensão desta situação, Bauman (2004) apresenta o conceito de "amor líquido", em que aponta a crise das relações afetivas causada pela fragilidade dos laços humanos na segunda fase da Modernidade. No estado líquido, as partículas não estão unidas umas às outras, estão livres, e de modo análogo, na Modernidade Líquida as relações sociais não criam vínculos, estão em constantes mudanças.

Em uma sociedade cada vez mais competitiva, em que se preza o individualismo como forma de aumento de rendimento dentro das organizações, rompem-se os laços emocionais; eles deixam de existir pelo medo da concorrência, que ameaça a pessoa de todos os lados. Segundo Freud, "o medo tornou-se grande a ponto de desprezar todos os laços e todos os sentimentos de consideração pelos outros" (Freud, 1921/1996, p.28).

A concorrência no mercado de trabalho mostra claramente que as relações sociais de trabalho e produção estão se tornando cada vez mais líquidas, como afirma Bauman. A defesa dos interesses individuais faz com que um profissional não confie mais em colegas, pares, subordinados e/ou chefes. É a era da disputa - disputa entre pessoas, entre instituições, entre áreas da vida. Assim, o indivíduo deixa de se doar para sua família para investir seu tempo em prol de contribuir com o objetivo de uma empresa, quando essa relação de trabalho é rompida, por uma demissão inesperada, se vê "sem chão", deslocado e lhe vem uma explosão de sentimentos, como: ingratidão, injustiça, não aceitação social e/ou até mesmo inutilidade. Ademais, aperda da renda geralmente provoca crises familiares e a sensação de impotência. Ele se depara com uma quebra da sua rotina e das relações humanas que tinha estabelecido no ambiente de trabalho. O que fortalecia essas relações eram os assuntos de trabalho, os ambientes compartilhados e os objetivos em comum, porém, com a demissão, isso deixa de existir. Nesse momento o indivíduo se vê sozinho.

O sentimento de desamparo que assola o indivíduo desempregado mostra como as relações sociais de trabalho e produção são relevantes para a construção de sua subjetividade, mas pode também despertar-lhe um olhar crítico que o faz compreender a fragilidade desta "proteção" e "do amor" oferecidos pelas empresas.

No mundo do trabalho, para o trabalhador, a realidade é uma enquanto a empresa está auferindo lucro com as 
atividades dele e é outra muito diferente quando os lucros dela começam a diminuir. Desde o momento de integração, campanhas e mais campanhas são realizadas pela empresa para gerar no trabalhador o sentimento de "pertencimento" e/ou até mesmo de ser um dos "donos do negócio", o que faz o indivíduo acreditar quehoras de trabalho dedicadas por dia à empresa serão recompensadas não apenas com remuneração e benefícios, mas também com solidariedade, amizade e reconhecimento profissional, o que gera no indivíduo um vínculo afetivo com tudo o que ele pensa que a empresa é. O que as pessoas esquecem na relação social de trabalho e produção é que ela não é permanente e não é baseada em valores humanos, mas em valores econômicos.

\section{Considerações Finais}

Aprofundar o entendimento do período pós-demissão com o auxílio do pensamento do sociólogo Zigmunt Bauman no contexto atual foi o objetivo deste trabalho. O desemprego é uma dura realidade, um enorme sofrimento que muitos indivíduos enfrentam no mundo competitivo e de tempos líquidos.

Para Bauman (2007, p. 99), todos, em algum momento, se deparam com situações cruéis que chegam sem aviso, "como um raio em céu azul" - quando não se espera o raio porque o céu está sem nuvens. O desemprego é um desses raios, chega gerando tormento, sofrimento e principalmente abandono por parte da organização e daqueles que faziam parte do convívio diário dos indivíduos.

Se os tempos são líquidos, tudo mais é líquido: a vida, a sociedade, o amor, o trabalho. Nada é feito para durar. Nesta situação, é preciso tentar obter respostas, todos os dias, para a pergunta sobre o que fazer. Talvez Bauman dissesse que, primeiramente, sobreviver, não se deixar afogar, porque o ser humano não é mais leve que a "água", ele pode flutuar se não souber nadar. Depois, tentar encontrar o rumo de alguma praia ou ilha. Tudo isso, só pode ser feito com mudanças nas relações e valores humanos que possibilitem o cultivo de um amor "sólido", que pode ter o efeito de transformações no estado das coisas.

O tema é muito complexo e este trabalho não pretendia - até mesmo por não ser possível nem desejável - fornecer respostas prontas, mas apenas uma reflexão sobre o que pode ser feito para a criação de novos tipos de relações sociais, principalmente de trabalho, com o grande desafio de elas poderem contar com o amor ao próximo, a ajuda e o alívio.

Como Bauman salienta (2004, p. 80), "a história ainda está conosco e pode 
ser construída", e se de fato, ainda não

terminou, ainda há esperança.

\section{Referências}

Bauman, Z. (2001). Modernidade líquida. Rio de Janeiro: Jorge Zahar.

Bauman, Z. (2004). Amor líquido: sobre a fragilidade dos laços humanos. Rio de Janeiro: Zahar.

Bauman, Z. (2007). Tempos líquidos. Rio de Janeiro: Jorge Zahar.

Bauman, Z. (2008). Vida líquida. Rio de Janeiro: Jorge Zahar.

CAGED, Cadastro Geral de Empregados e Desempregados. Disponível em: http://exame.abril.com.br/economia/brasil-fecha-132-milhao-de-vagas-formais-detrabalho-em-2016/acesso em 25 jan. 2017.

Caldas, M. P. (2000). Demissão: causas, efeitos e alternativas para empresa e indivíduo. Atlas.

Castel, R. (1998). As metamorfoses da questão social: uma crônica do salário (Vol. 6). Petrópolis: Vozes.

Castelhano, L. M. (2006). A perda do emprego, suas implicações subjetivas e as consequências para o laço social: uma contribuição psicanalítica. São Paulo: PUC Pontifícia Universidade Católica.

Chahad, C., \& Chahad, J. P. Z. Z. (2005). Os impactos psicológicos do desemprego e suas consequências sobre mercado de trabalho. Revista da ABET, 5(1).

Dos Santos Costa, V. (2015). "Tempos líquidos": desafio para a nova evangelização. Theologica Xaveriana, 65(179).

Eisenberg, P., \& Lazarsfeld, P. F. (1938). The psychological effects of unemployment. Psychological bulletin, 35(6), 358. https://doi.org/10.1037/h0063426

Frattari, N. F. (2008). Insegurança e medo no mundo contemporâneo: uma leitura de Zygmunt Bauman. Sociedade e Cultura, 11(2).

Freud, S. (1996). Psicologia de grupo e outros trabalhos. Além do princípio de prazer, Psicologia de grupo e outros trabalhos. Edição Standard Brasileira das Obras psicológicas completas de Sigmund Freud, v. 18. (Texto original publicado em1921).

Hayes, J., \& Nutman, P. (1981). Understanding the unemployed: The psychological effects of unemployment (Vol. 223). Routledge. 
Jahoda, M. (1982). Employment and unemployment: A social-psychological analysis (Vol. 1). CUP Archive.

Machado, H. V., Hernandes, C. A.\& Moraes, M. (2008). Explorando significados da demissão. Gestão \& Planejamento-G\&P, $1(10)$.

Pereira Basílio, M. (2010). Reseña de Tempos líquidos. Sociologias, 12(23).

Seligmann-Silva, E. (1997). Saúde mental e automação: a propósito de um estudo de caso no setor ferroviário. Cad. saúde pública, 13(supl. 2), 95-109. https://doi.org/10.1590/S0102311X1997000600009

\section{Os autores:}

Maria Gabriela Pires de Lacerda Lima, graduada em Administração de Empresas (CESUC/GO). Email:gabilacerda1@gmail.com

Roberta Almeida Elias, graduada em Redes de Comunicação pelo Centro Federal de Educação Tecnológica do Estado de Goiás (CEFET). Email: robertaellias@gmail.com

Rhennan Lázaro de Paulo Lima, graduado em Administração (FAI/GO), docente no EBTT (IF Goiano). Email: rhennan.1@gmail.com

Serigne Ababacar Cissé Ba, Administrador. Docente no Programa de Mestrado Gestão Organizacional /UFG/RC. Email: serigneababacar@hotmail.com

Recebido em: 08/05/2017

Aprovado em: 28/12/2017 